\title{
Reflections on Doing Cross-Cultural Research Through and with Visual Methods
}

\author{
Kei Yan Leung
}

\section{Introduction}

Language is the dominant medium on which social scientists rely in their research practices; they use language both to create knowledge and in their choice of interpretative methods to communicate this knowledge (Davies \& Dwyer, 2007). However, our daily lives are composed of many different dimensions, and not all knowledge is reducible to language. Instead of seeking singularity and certainty to make sense of that one reality through language, there are multiple realities, and we need new ways of knowing in order to navigate through the diffuse and messy world (Law, 2004). When we aim to understand the mindsets and practices of interviewees, focusing solely on spoken words may be limiting. In the context of my own research, farmers do not necessarily engage in

K. Y. Leung $(\varangle)$

University of Natural Resources and Life Sciences, Vienna, Austria e-mail: natalie.leung@boku.ac.at 
word-based cognitive reflection when they interact with plants, animals, soils or tools.

Instead of focusing solely on how we communicate our thoughts and experiences through language, scholars have been shifting their focus to more-than-representational experiences such as emotions, affects and sensuous experiences ${ }^{1}$ (Law, 2004; Lorimer, 2005). The relational, emotional and affective aspects in research practices regarding the interactions between humans and non-humans have been increasingly acknowledged (e.g., Campbell et al., 2019; Hitchings, 2003; Krzywoszynska, 2016). In addition to increasing explorations on methods that invoke emotions, different attempts have also been made to theorize and interpret emotions and affect (Anderson, 2006; Harrison, 2000; Pile, 2010; Thien, 2005; Tolia-Kelly, 2006). In these works, the world is conceived as full of sensibilities, and researchers seek ways of knowing beyond words and languages through openness and reflexivity. With the assumption that knowing is more-than-representational by considering both representations and affective, sensuous experiences, this chapter uses the context of cross-cultural research to explore the limitations of knowing solely through language.

Cross-cultural research is a fertile ground used to explore the role that meanings beyond language play in our understanding and engagement of the world. When conducting research in one's own native language, the researcher might also struggle with language, but they focus more on making sense of how discourses and practices work together (Krzywoszynska, 2015). In the context of cross-cultural research, the researcher does not instinctively know all the experiences that are associated with words; knowing also involves the process of understanding the emotive and embodied relationships that are specific to the language, place and cultural practices (Krzywoszynska, 2015). When language cannot give a full account of experiences, it unfolds the opportunity for cross-cultural researchers to seek alternative understandings of the interviewees than a local researcher might do. In this sense, a cross-cultural

\footnotetext{
1 There is an extensive body of literature on non-representational and more-than-representational approaches that do not prioritize the role of representation and reasons, they also take into account the role of practices, affects, emotions to account for the interactions between humans and non-humans (e.g., Anderson \& Harrison, 2016; Lorimer, 2005).
} 
researcher is perhaps similar to a blind person: they might not be able to see through direct vision like a local researcher, but they can see hidden meanings through a range of sensitivities and sensibilities that a sighted researcher may otherwise neglect. Indeed, it will take longer for a cross-cultural researcher to understand their interviewees because of the cultural and language differences. They will also learn less about certain things because the cultural and language gaps just could not take them there. However, they can potentially learn a wider range of realities, or even participate in the making of those realities, because they are outsiders who always seek more thorough explanations from the interviewees.

Visual methods have the potential to supplement the limitations of verbal research methods in both cross-cultural and same cultural settings. Our vision is not only limited to an objective process that is associated with discourses, meanings and judgements. When we see, we also develop subjective experiences such as sensibilities, and embodiment (Rose \& Tolia-Kelly, 2012). Undertaking interviews with images allows people to go beyond the verbal thinking mode and include a wider aspect of their experiences at the emotional level, or layers of experiences that cannot be easily put into words (Bagnoli, 2009).

In addition to data collection, visual methods also have the potential to improve scientific explanation and understanding of scientific knowledge to both scientific and non-scientific audiences (Rodríguez Estrada \& Davis, 2015). Scientists have been using graphs and figures to communicate scientific results visually for centuries (Tufte, 1997, cited by Darnhofer, 2018). More recently, visual communications are also increasingly used to connect non-scientific audiences. For instance, Bartlett (2013) used cartoons to communicate her research findings about issues related to misconceptions of dementia. She noted that cartooning helped to present serious topics in a more playful way, making it easier to engage audiences (Bartlett, 2013). Darnhofer (2018) found that using comic-style posters to share preliminary findings with her research participants was effective in engaging the participants to share their feedback and facilitate more in-depth discussions of the research topic. 
In this chapter, I will reflect on my experiences as a cross-cultural researcher during my field work in Japan, where I conducted interviews with farmers using photo-elicitation to understand how they build relationships with artworks and their farming. As a Hongkonger, I had previously worked at the field site for three months on an art project about farming. However, I am not able to speak Japanese, so I worked with a local interpreter to conduct interviews with farmers with Japanese-English translation. Through the experiences of working with photo elicitation to collect data, and the attempt to convey research results through illustrations, I argue that visual methods help to uncover different realities that are beyond the scope of linguistic relevance, but nevertheless, fundamental to understanding the mindsets and practices of farmers.

In the following, I start by providing a brief account of how I applied photo elicitation in my doctoral research. I then first discuss how experiencing the challenges of communication brought by cultural differences pushed me to rearrange the interview questions. Second, I elaborate on the limitations of translation in communicating experiences, thoughts and emotions that are tied to cultural practices. Third, I illustrate how photo elicitation helped to unfold different layers of experiences by the farmers during data collection. Last but not least, I discuss the potential challenge of conveying results from research in Japan to non-Asian audiences, and why I combined visual illustrations with verbal quotes to give a more in-depth portrayal of the experiences of Japanese farmers to Western audiences.

\section{The Study: Talking About Art Through Photo Elicitation}

In my doctoral research, I used photo elicitation in interviews to explore how Japanese farmers build relationships between their farming and artworks. My aim was to understand how farmers perceive artworks and the potential impacts of art on their farming. The study was conducted in Tokamachi (a remote mountainous area in Northeastern Japan), in two respective field works in the winter of 2019 and 2020. I selected 
this particular area because it is where the Echigo-Tsumari Art Triennale (ETAT) takes place. Similar to many rural areas in Japan, Tokamachi is facing the problem of dwindling population and increasing numbers of abandoned houses and fields (Kitagawa et al., 2015). ETAT was the first art project designed to address the issue of rural revitalization in Japan; it is the world's largest rural art festival. By placing art installations in abandoned landscapes and rice fields, ETAT uses art as the means of reconnecting with traditional farming practices, and the farming landscape they produce (Kitagawa et al., 2015). Through these, ETAT aims to invite urban visitors and local residents to rediscover existing but neglected local cultural and natural resources, and reflect on their values.

In total, I interviewed 25 farmers and an artist who has been working with local farmers to market their products. The farmers were selected based on their engagement in more agro-ecological farming practices than mainstream farmers. These agro-ecological practices are broadly defined by the way they substitute environmentally sound inputs and practices for industrial ones, and reconnect with traditional practices that are more well-suited to local agro-ecosystems (Gliessman, 2017). In Japan, farming is dominated by small-scale, mechanized rice farming under the co-ordination of state-supported Japanese Agricultural Cooperatives (JA). JAs manage government subsidies, provide advice and input, and govern standardized, industrial rice production and sales (Esham et al., 2012; Mulgan, 2005). The state-initiated agricultural liberalization since 1990 enabled the emergence of this group of agroecological farmers who intentionally engage in more sustainable farming practices. This group of farmers were selected because their farming practices resonate with ETAT in re-signifying dying, traditional villages through innovation and re-interpretation of traditions. Such similarity suggested that these farmers might be more able to relate to ETAT's artworks. However, this is not a point that my research can prove because I did not interview mainstream farmers.

The interviewed farmers were selected through snowball sampling. Based on the information of the respondents, it is believed that these 25 farmers are most, if not all, of the agro-ecological farmers known in the area. Among these farmers, five of them work for ETAT on a part-time basis to take care of fields that host artworks; the rest of the 
farmers work on fields that do not have artworks and they were not involved in the selection and management of the artworks. This reflects the fact that that most agro-ecological farmers are not directly involved in the artworks or the art festival. After the interviews in Winter 2019, I subsequently carried out three group discussions with them to deepen my understanding of how they make sense of selected artworks that are related to agriculture and landscape in Winter 2020. Similar to many of my research respondents, the interpreter moved to the area from Tokyo to seek a traditional lifestyle in the countryside.

During the first field work, in Winter 2019, I interviewed the farmers with nine pictures of seven selected artworks. The artworks were selected mainly based on their high publicity in ETAT, conspicuous locations on rice fields, and the link to traditional agricultural practices in Japan. In the pre-designed interview guide, I started by asking briefly about their farming background, i.e., how they started, and about their farming characteristics and challenges. The rest of the questions were guided by photo elicitation: I showed the farmer photos of artworks, invited them to choose one that they wanted to talk about, and asked them to share how the artwork is relevant to their farming.

\section{Adaptation of Interview Questions}

The first few trial interviews were a mess, and I very quickly realized there is a gap that limited my understandings of what the interviewees said. The questions about the artwork were too difficult and abstract for some of the farmers. They were anxious about not being able to give a 'correct' answer about what the artworks convey. Responses like 'I know nothing about art', 'I am just a farmer, I am not interested in art' were common. Although Tokamachi is dotted with artworks, art is still something unfamiliar and distant to some of the farmers, because they consider aesthetic experiences as something separated from ordinary experiences. Originally, I thought that the multivocality and abstraction of art could invite the farmers to relate to it in a diverse way, but it turned out that the indirectness of art made some of them feel anxious about not being able to give a model answer. I tried to understand why they are not 
interested in art; we were exchanging words through the interpreter but we were not able to communicate. They were trying to understand what my strange questions were trying to capture, and I was trying hard to understand the meaning of their answers. Gradually, I realized that what was hindering the communication was my lack of understanding about their ways of being a farmer in the area; I was not able to relate to their mentalities, and to their emotional struggles about being an outsider in the group-oriented village culture in Japan.

For instance, in the following conversation, I originally intended to find out why the farmer was not interested in the artworks and what kind of qualities the artworks lack. At the beginning when I was not aware of the social pressures they were referring to, I had difficulty to logically relate to the distinction they made between artificial things and cultural events/traditions:

$Q$ : Why are you not interested in the artworks?

$A$ : I don't understand the meaning of the works... I am not really interested in those art, so I never thought of anything about them. I have seen some of them, but it is so awkward to put artificial things in nature I don't like the idea, it feels so unnatural. I don't get anything about them, I love nature more than artificial things.

$Q$ : What about Matsuri? It is more of a cultural event.

$A$ : Those ceremonies with fire, all the traditional events, that maybe seem like art to foreigners, I think they have meanings in their cultural background, so I can understand them.

Q: How do you understand them? Does it mean you do not like the artworks because they have no cultural background?

$A$ : From those cultural events, I don't know if I like or dislike them or not, I just accept them. I accept them because the meanings are inherited from the past, I just accept the ideas. But for those artificial things, they are just so awkward, so I don't understand any of them.

$Q$ : You just mentioned that the cultural events are meaningful because they are from the past... what do you mean by just accepting the ideas because they are from the past?

A: (thinking about it hard) Hmm... I think to follow those traditional events, rules and life they have here... it's about respecting the life here... I am following local rules and habits from the past, just like the locals are following their lifestyle from the past. I started growing 
rice and veggies because my neighbours and the elderly also do it in this way, it is really important for me to follow the kind of life they have had for long time, to me this is the meaning of living a local life... in this village we prepare rice shooting collectively and they would use chemicals, I cannot avoid it. It is part of the cooperation. If I do not follow, I will be ditched and complained about by the community. To assimilate in the community and receive support from others, I have to accept something that I don't agree with. For me, it is really important to live in this village peacefully and happily without having any troubles with villagers.

It turned out that the context behind this farmer's rejection of the artworks and acceptance of traditions related to their situation as an incomer in the village and the emotional pressures to assimilate into the community and local traditions. I came to understand that the relationship between art and farming is not just about how the art installation itself is related to the meaning of their farming practices. It involves far more diverse relationships that are connected to their mode of life as a farmer who engages in agro-ecological farming practices and a newcomer in the village, and the emotions and feelings that are tied to it.

As a cross-cultural researcher, I needed to know more about their form of life in order to understand the possible relationships they would develop with the artworks. Therefore, I changed the arrangement of the interview questions, I allocated more time to talking about their farming values and practices before moving to the questions of art. Not only did this help me to make better sense of their farming life, talking about things they are more familiar also helped to empower the farmers and reduce the anxiety of talking about art.

\section{The Difficulty of Translating Life and Practices Under Cultural Differences}

Although rearranging the questions inspired more diverse discussions with the farmers over the artworks, I noticed that the limitations of translating emotions and local experiences through language were still present. 
After all, I still depended mainly on words to communicate with the farmers and understand how they saw the photos. I noticed that even a perfect word-for-word translation did not help me to proceed smoothly with the interview. As a foreign researcher, I simply lacked the cultural sensitivity and fluency to ask the question in a culturally relevant way to delve into topics in which I was interested.

This is illustrated in the following extract of a group discussion, where apparently the farmers and the interpreter have a different understanding of 'nature' than my original question intended. They do not see nature as separated from humans; they also see humans as part of nature in their cultural concept of Satoyama. When I framed my question based on the western concept of the human/nature split and tried to understand how they make sense of such distinction, it did not lead me anywhere. My question got lost in translation because the interpreter and the farmers were not able to relate to my question:

(Q: me; I: interpreter; A: interviewee)

Q: In your opinion, what is landscape? The artificial rice terrace or the wild forest?

I: It is a hard question, it's not difficult to translate but the question itself is difficult to understand...

Q: Do you make a distinction between artificial rice terraces or natural/wild forests?

A: We called it satoyama, there is no translation. It means the middle part of wild nature and where people live. The landscape here or the future of here is the satoyama, that's why in the mountain there are rice terraces here, we call it satoyama view.

Q: Earlier some of them mentioned being captured by some beautiful moments in life; is that because the nature/landscape you see involves human participants It involves villagers, community, and you also live in this environment...

I: I think it depends; it is different for everyone. What do you want to ask?

Q: I just want to know if they find the nature here beautiful because they are part of it? Like the example of going to the wild nature: countryside people go there and they still find it beautiful, but they cannot live 
there, so those kinds of moments that they think as beautiful won't last. But for people here, they can observe the changes in different seasons; is that because they live a life here/they share a life with nature?

$A$ : When you go to the deep mountain here, if there is a path, it means there was life there many decades ago. I see the beauty when I feel the traces of humans, just like I also feel the beauty from the piece of farmland that elders just weeded by hand, I feel the beauty of their work.

These moments were clumsy and awkward, because I just could not find words to communicate my thoughts. It is not because we cannot find the 'right words', but more that I do not have the cultural context to understand their connection with nature in their everyday lives, and therefore their experiences associated with these connections. Meanwhile, the farmers also did not understand what I was asking because the nature/human split simply does not exist in their cultural understandings of landscape. Through these experiences, I realized that there are limitations in language that I simply cannot transcend as a cross-cultural researcher.

Cross-cultural researchers in social sciences tend to focus on solving 'problems' in translation and making communication effective (Turner, 2010). For instance, how to get precise translation, a correct version of an interview transcription to minimize the discrepancy caused by language differences (Turner, 2010). Many social scientists are often preoccupied with words because they tend to believe that the world is static, definite and predictable, and through precise words they can discover these definite states that exist out there in reality (Davies \& Dwyer, 2007; Law, 2004). However, my fieldwork experiences clearly showed that the world is more complex and textured, so that the challenge is less in finding an exact translation, than our capacity to understand what farmers try to convey.

Instead of getting frustrated by not being able to maximize accuracy in language, I chose to be reflexive about the role and limitation language plays in cross-cultural research. The language differences made explicit the cultural dimension and demonstrated that meaning is made 
outside of literal translation. Pereira et al., (2009, p. 5, cited in Krzywoszynska, 2015) believed that 'a lot of insight can be found, and a lot of knowledge can be produced, through explicit and critical reflection on the challenges and incommensurabilities of language difference'. For instance, there is no such concept of 'Satoyama' in English. It resembles the concept of 'countryside' but is more than that. If it is translated from Japanese to English literally, it means 'the area between mountains and human settlements'; it is covered with managed woodlands and terraced rice fields (Brown \& Yokohari, 2003). However, the translation neglects the values of nature implicit in the concept, that human communities (sato) and non-human nature (yama) coexist side-by-side in harmony (Yokohari \& Bolthouse, 2011). The non-nature/human split does not only shape traditional agricultural practices in Japan, it also shapes the spiritual connections and respect farmers have with nature. There are also Satoyama landscapes in various places in other Asian countries like China. The distinctiveness of the Japanese one is the spiritual ties to nature, in which the Japanese believe that there are eight million deities present in nature (Iwatsuki, 2008). As a buffer zone between human settlements and deep mountain areas (okuyama), the Satoyama area is where they set up shrines to worship the deities so as to ensure coexistence and their guardian in daily life (Iwatsuki, 2008). If I just adhere to the mainstream western approach to strive for a precise translation and omit the cultural understanding that farmers have of nature, the possibility of exploring different approaches of nature/human relationship in another culture could be easily overlooked.

In addition, I also found that the language differences highlighted affective experiences that are tied to cultural practices. Feelings and affects do not just come with words; they are entangled with the specific social and cultural life of the interviewees. Although I went to the field with a local interpreter who acted as a vital cultural broker, it was not easy to convey feelings across cultural and language barriers. For instance, in the conversation about landscape, when I was trying to understand how farmers categorize and distinguish human and nature, the farmers were relating it to how they feel the beauty from the collaboration between humans and nature in an affective way. However, a perfect linguistic translation did not make me experience the feeling of beauty they have experienced. In the following conversation, I was still trying hard to 
understand from the interpreter the kind of beauty they were referring to:

Q: What are the things that they found beautiful? What is it that captured them?

I: There were moments that nature and the view just overwhelmed us, those are moments that we are not able to tell what captured us... I just asked them about it, it is not about any specific thing but the whole atmosphere at that moment just captured us in our daily life.

It is therefore important for the interpreter to be sensitive about cultural differences; they have to understand peoples' feelings, reframing them and making them 'reasonable' to researchers from a different cultural context (Turner, 2010). ${ }^{2}$ However, in the process of making feelings 'reasonable', the quality of the feelings described is incomparable with how it was experienced (Harrison, 2007). One of the respondents of Giustini (2019, p. 195) illustrated the limitations of language when it comes to the expression of emotions: 'sometimes we can't find the linguistic or cultural expression that would match the same level of emotion, but we try to do as much as we can to impact the audience'.

\section{Opening up New Ways of Seeing Through Photo Elicitation}

The use of photography in research is not something new; it first appeared in 1957 to study how different ethnic groups adapt to residence and new forms of work in urban factories (Collier, 1957, cited in Harper, 2002). Since then, photography has been increasingly used in various social sciences disciplines. There are different methods, as photos can be provided by the researcher or taken by research participants through

\footnotetext{
2 The roles and influences of interpreters in cross-cultural research is a subject in its own right, and this book chapter is too limited in scope for more in-depth discussions. When one can speak a particular language, it does not automatically mean that you can represent a culture. The sensitivity to cultural differences is not only shaped by one's cultural background, it is also shaped by one's social background, positionality, personality traits, language proficiency, and so on (Turner, 2010; see also: Caretta, 2015; Temple, 2002; Temple \& Young, 2004).
} 
a camera handed to them. Also, different terms, such as photo voice, participatory photography and reflexive photography, have emerged to denote the varying use of photography in research.

Photo elicitation is broadly defined as a qualitative research method where photography is used to enrich and complement research data (Harper, 2002; see also Axinte, this book). The advantages of using photography in research are well documented, including research about farmers, or those in natural resources settings (e.g., Beilin, 2005; Sherren \& Verstraten, 2013; Sherren et al., 2012). For instance, visual materials prompt respondents to reflect on things that they did not get to discuss in talk-only interviews (Rose, 2014). By putting farmers in control of the conversations that emerged, photo elicitation helps researchers to study complex issues that can be very personal and deeply held by farmers (e.g., farm landscape management), in a manageable and sensitive way (Sherren et al., 2010, 2012).

In photo elicitation interviews, pictures are used to invoke comment and discussions in the course of interviews, and therefore to make various realities visible in data collection (Banks, 2001; Rose, 2014). This approach uses the structure of showing, and then telling what is shown; the image is simply used by the researcher as an inscription device to visualize a certain reality to research respondents (Rose, 2014). Even if the pictures are taken by the respondents, researchers tend to focus more on what is pictured and making meanings by working with what the image shows. For example, photography is also used to study farmers, but it is used in a similar way to trace knowledge and experiences that the researchers are looking for. Harper (2001) used aerial photos of farmlands and historical photos to interview elderly farmers about their memory and interpretations of farm life in the 1940s. By using the photos to make the old way of farming visible again, Harper (2001) elicited rich details from the interviewees about technological transition to industrial farming in the US, what social relationships were like before the transition and, more importantly, their feelings about those old days.

However, Rose (2014, p. 31) finds that in visual research methods there is an almost total neglect of the 'symbolic and communicative components that are specific to the culture'; she refers to these components as visuality. Visuality is the cultural construction of visual 
experience; it means what the respondents see, how they are able to see, and how this seeing and unseeing are governed by their cultural understandings of the messages inherent in the images (Foster, 1988, cited in Rose, 2014). In my research, my unseeing of the seeing of the farmers has, in many ways, highlighted how their seeing is specific to the social and cultural contexts of Japan.

Initially, I aimed to use the photos to elicit more information and make it easier for the farmers to talk about relationships between art and their farming. In other words, I also used the photos as an inscription device to confirm the reality that I was looking for, without taking into account how the farmers see. Indeed, the photos helped a lot in relating the artworks to the daily life of the farmers. The combination of artwork and landscape in the photos encouraged them to look at the artworks as pictures or sceneries and share their perspectives freely. It turned out that the photos encouraged different imaginations among the farmers, and they shared more insights than what messages the photos conveyed to them. This was especially so in the case of those who said they knew nothing about art at the beginning of the interview. For instance, they related the photos to the past farming scenes in the area, the resemblance with their current practices in terms of values and actual things they have created like farmhouses, and their vision of the future of the local area. Indeed, their seeing was not just restricted by the art piece itself, but also the background of the artwork and the combination of the artwork with the background. Some of them also built relationships between their seeing and farming life, in which they projected themselves to certain artwork and saw how it signified the rhythms and characteristics of their farming life.

Through these experiences I found that the cultural differences of how some of the farmers and I see visual materials in the photos can serve as a good opportunity for me to understand the social life of the farmers and highlight their associated affective and sensuous experiences. When they talk about the images in the interview, to me it is more than just about what the images show, but also about how they see the images in certain ways. The fissure between the seeing and unseeing among us provided rich material to uncover different realities; this might well 
remain implicit and thus hidden in research conducted in the same cultural context.

For example, when I saw artistic elements from the photos of traditional festivals where people are playing traditional Japanese musical instruments, to some of the farmers those are cultural events that worship the spirits of dead people and convey the meanings of assimilation. Some of them saw the projection of traditional cultural landscapes in Japan from the photos, I saw nothing but just some forests with abandoned fields. It is these fissures that inspired me to ask more questions to seek clarification from the taken for granted but unobservable thoughts of the farmers. As a foreign researcher who lacked understanding about how Japanese farmers make sense of farming, this has opened up different realities of local farming context to me. These are realities very different from the one I encountered from doing a literature research, in which the literature mainly highlights the challenges farmers face under different structural forces in Japan.

By sharing how they see the pictures and what the pictures visualize to them, the farmers illustrated how they make sense of their farming life through a different form of knowing, one that does not separate reasoning, feelings, affective and sensuous experiences. These more-thanrepresentational understandings are embodied sensations, such as the sight of rice terraces, or the physical difficulties and embodied feelings of working on the land.

I also found that the point of using visual method is not at all about filling the difference between language and experiences resulting from the gap in cultural understanding in cross-cultural/same-cultural research to make communication 'adequate'. There is never a translation where language is 'adequate', especially if we also take more-thanrepresentational experiences into account (Harrison, 2007). What is significant about using visual methods in both cross-cultural and same cultural research is that it traces the limits and possibilities of mainstream social analysis, and inspires researchers to stop preoccupying themselves with language, and start considering how meanings beyond language can enrich our understanding of our research subject. The following are some examples of how the use of photos in interviews helped to uncover different layers of meanings through the seeing of the farmers and my unseeing. 
Ikeda was amazed by the photo of the 'Rice House' in Fig. 9.1. He saw the life of a household in the frame, he saw a kitchen, a living room and a family living there. He related the picture to the concept of Tanaka, which literally means a 'house surrounded by rice terraces', and he saw the traditional view of the local village hundreds of years ago from the photo. As a non-Japanese farmer, I was not able to see the rich cultural connotation that the 'Rice House' carries. Yet, such unseeing captured my attention towards the nostalgia that Ikeda had towards such traditional landscapes, and the disappointment he had when he gave up some rice terraces last year, as cultivating them was too physically demanding. His seeing from the photo did not allow me to experience the same emotional connections he has with the landscape, but it highlighted the importance of considering the emotional aspects that are keeping farmers motivated to persist traditional, labour-intensive practices.

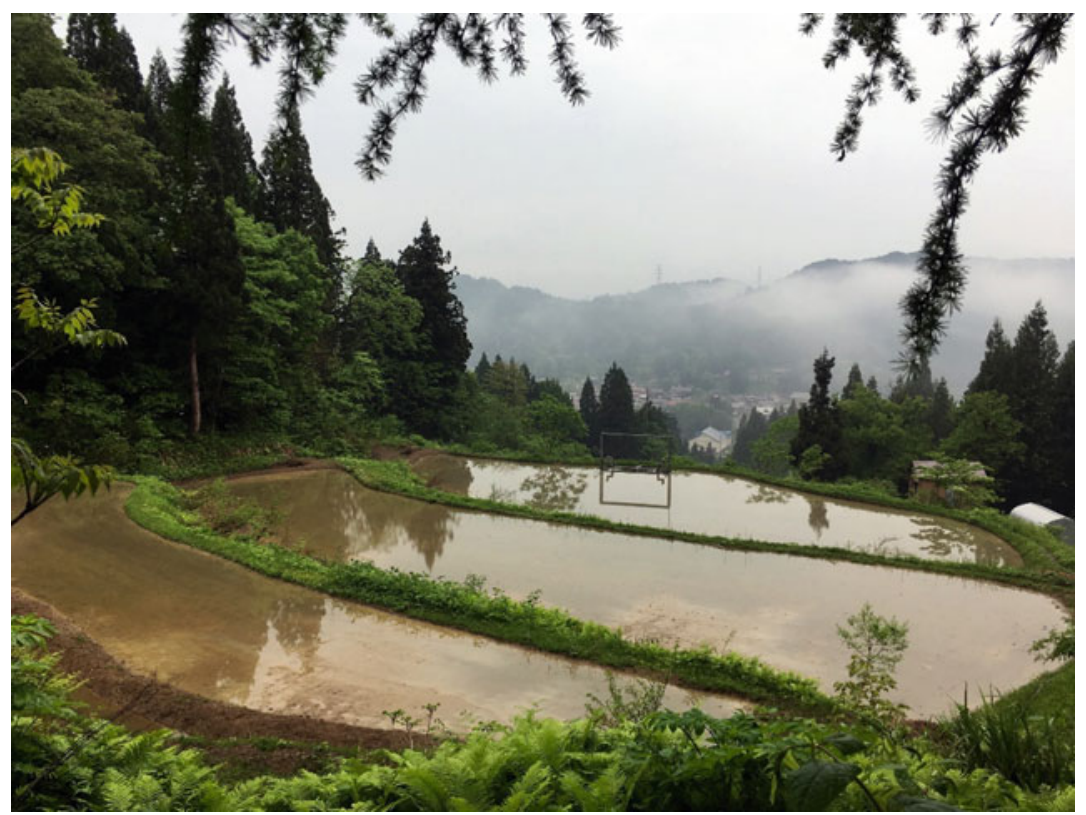

Fig. 9.1 'Rice House'-the metal frame merges with the landscape and rice terraces to form an harmonious picture in different seasons (Source Photo by author) 


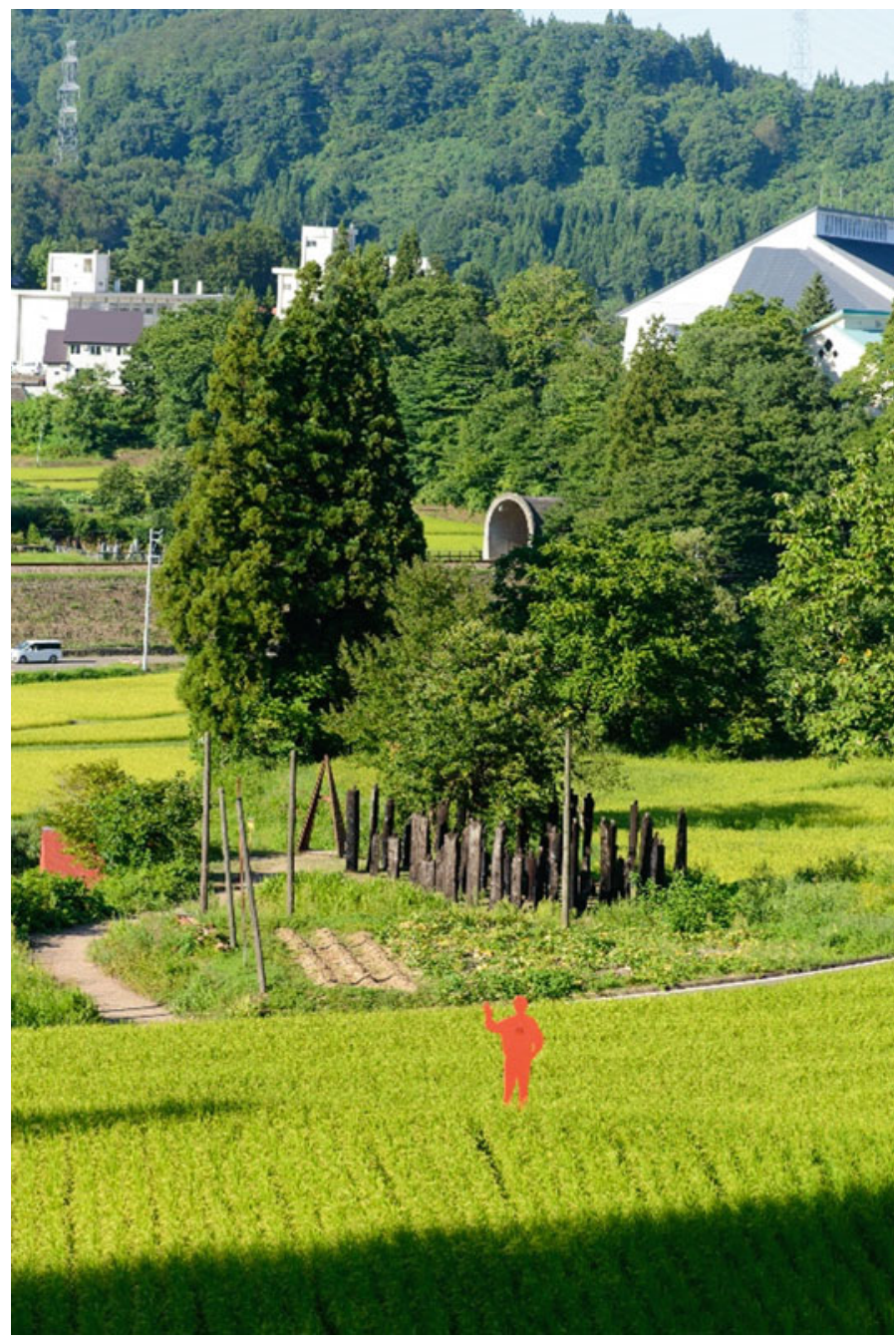

Fig. 9.2 'Scarecrow Project' - the red silhouettes represent the past scene of the family of the landlord working on their ancestral land (Source Calvin Wong)

Morita takes care of the rice fields hosting the 'Scarecrow Project' (Fig. 9.2, above). He was working on the fields every day; he did not think much about the artwork because it was too connected 
to his daily life. Instead, he focused on the uneven growing conditions of the rice field in the picture. The rice field has experienced mudslides, resulting from rice fields in higher terraces being abandoned. They damaged the field, making it difficult to work on because some parts are deep and muddy. He related the artwork to these embodied experiences of working the field, and this reminded him of the need to keep rice fields active to preserve the landscape. This is in contrast to all I could see from the picture: the red silhouettes. Yet these red silhouettes did not matter to Morita at all. All the photo reminded him of were the uneven growing conditions of the rice plants. From his words, I was able to know the hardship he had endured when working with this field, but I was not able to experience his embodied experiences of physical fatigue and the emotional connections with landscape through language. However, his seeing and embodied feelings uncovered his sentiment towards preserving the Satoyama landscape, which is getting lost because in this mountainous area rice fields are increasingly abandoned. As mentioned earlier about the Satoyama landscape, to local farmers the loss of the landscape is not just about its physical disappearance, it is also the breaking up of human-nature collaboration and the spiritual connections. To him, the physical fatigue he was enduring was the bridge to rebuild this collaboration, it was associated with the emotional connections to the culturally meaningful landscape.

The strength of how visual materials are more capable in stressing emotional experiences became obvious when Shibata and Keiko talked about their feelings towards snow, respectively through words and picture. The lack of emplaced experiences made it too abstract for me to relate to Shibata's feelings about snow. Also, he believed that as a visitor, I would not be able to relate to the beauty they find from the snow in the area.

It is the light and darkness about the beauty. If you don't live here for a whole year, you don't know how tough it is to live through the winter. When you just come and see the beauty of snow in winter, the joy is different, and you also would not feel our thankfulness to spring. (Shibata) 
Although I am not able to share the same feeling towards the beauty of snow with the farmers, the emotion related to seasonal changes was made explicit when another farmer, Keiko, relieved the feelings she experienced from snow, triggered by a photo from the artwork 'Human re-entering nature' (Fig. 9.3) in winter. Her experiences signified the emotional changes and embodied experiences of living a rhythm of life that is dependent on seasonal changes. For instance, the relief from working on terraced rice fields that are not accessible by machinery in summer, and therefore the calm and stillness she associated with snow in winter.

I wonder what he is thinking, I can imagine many things by looking at him... I wonder why he is standing like this, nowadays people don't stop, they are all moving around. But when snow comes, we feel relieved because winter has finally come. Maybe he feels relieved to see the snow and he can finally take a rest. It is such a good picture. (Keiko)

\section{Conveying Research Results Through Visual Illustrations}

The cross-cultural position as a non-Japanese person has helped me to unfold different layers of meanings that might remain hidden to a Japanese researcher working in their own cultural context, as they might be too obvious to merit mentioning. However, as an Asian I also faced the challenge of adequately conveying the research results to non-Asian audiences through words. ${ }^{3}$ It was already difficult for me to 'fully' understand the farmers given the cultural differences between Hong Kong and Japan. As a result, the words of the farmers had already gone through a first layer of cultural translation by the time the interpreter translated the words to me. There would then be a second layer of cultural translation when I communicate my research results through words to western audiences, who are even more culturally distant to Japanese farmers than I am as a Hongkonger. The idea of visualizing interview quotes first emerged

\footnotetext{
${ }^{3}$ Communicating research results to non-Asian audiences is necessary as the research is intended for publication and doctoral examination in a western context.
} 


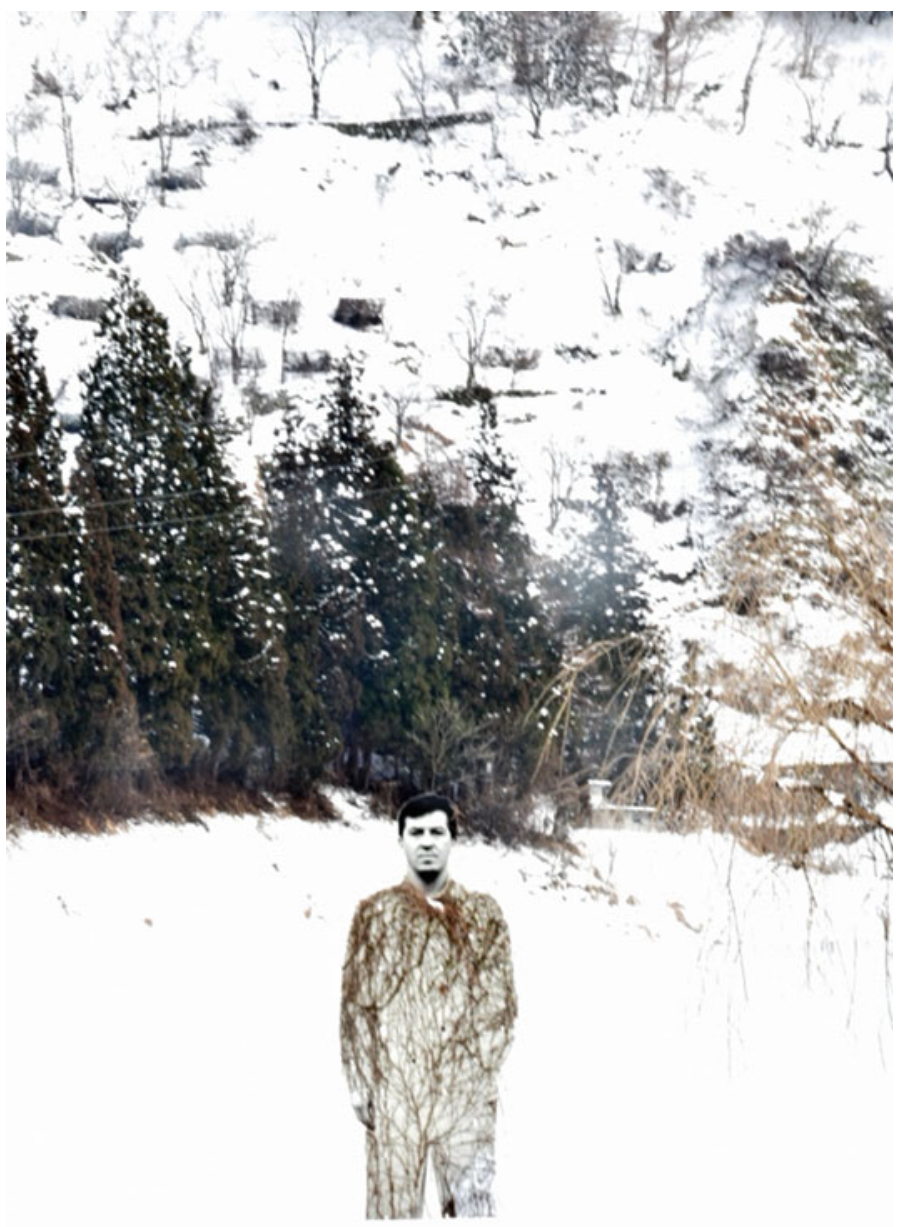

Fig. 9.3 'Human re-entering nature', Winter-a 4-metre high human figure that changes with the season (Source Anna Mak) 
when I checked if the interview transcription is 'correct' with the interpreter. She told me that some of the quotes sound right literally, but the spirit and the emotion of the speaker is gone in the English sentences. For example, when Yoshida spoke in the following quote, the emphasis was on the positive and thankful feelings for being able to work together with the beautiful landscape to produce food. However, the interpreter felt that these emotions were lost, as the English translation sounded more like he was frustrated by the physical workload, which he uses to justify the use of chemical pesticides. She thought that it was important to emphasize the positive attitude through a supplementary note.

I always enjoy farming in the mountains, I feel proud that my rice and wheat came from these beautiful mountains, and I preserve the Satoyama landscape... I am taking care of the abandoned farmland, but it is taking too much labour and time to do the organic way, I cannot do all the work by myself, I have to use chemicals to weed. I want to reduce the chemical usage on wheat, I am looking for a good way to use them. (Yoshida)

Therefore, I thought of working with a local Japanese artist, whom I interviewed during the first field work in Winter 2019, paying her to produce graphic illustrations of selected quotes. I could use the illustrations to supplement the farmer's verbal quote and depict the scene of how particular experiences were understood by the farmers. Similarly, Dahl et al. (2012) used a graphic novel to retell the life stories of five homeless people they interviewed in academic research. Through portraying the life events preceding their homelessness, and how they experienced these events emotionally, the graphic illustrations draw the attention of a wider group of audiences to the complicated social issue of homelessness.

Together with the interpreter, we therefore identified three interview quotes in which the emotional and sensuous experiences of the farmers are especially absent in the English translation. Afterwards, I arranged a meeting with the local artist, in which the interpreter and I discussed these quotes with the artist and shared with her how the emotions and spirits of the farmers were lost in translation during the interviews. I invited the artist to draw three illustrations based on the three quotes; I also invited her to convey the quotes in her way. Shortly after the 
meeting, the artist presented me a first draft with five illustrations. I picked three illustrations that I thought fitted most with the quotes, and I gave her some comments and suggestions for aspects that I thought could be further highlighted in the illustrations. After that, she incorporated my comments, revised the first draft and delivered the final illustrations to me.

As a rare artist working with local farmers in this remote rural area, the artist has been using artistic design to help local farmers to market their products to both local and urban customers The artist therefore provided highly valuable thoughts and ideas because she understood the language and experiences of local farmers, and she is also experienced in converting the language of farmers to non-farming audiences through visualization. Rodríguez Estrada and Davis (2015) point out that not all visualizations are effective communications, and visualization is also not a blind process of integrating written discourses with visual illustrations. It is important for the communicator to not just understand the written discourses, but she should also be able to connect with non-specialist audiences through their language. In the design approach of the artist, she first understands the farming approaches of farmers, then she helps them identify the distinctiveness of their products. Therefore, she is familiar with local farming landscapes and the settings of the farms of local farmers, and knowledgeable about the farming approaches and practices of local farmers. In her design work for local farmers, she communicates these aspects of local farmers to both local and urban customers. Through these experiences and background, she can utilize the techniques in graphic design, e.g., composition, colour, layers, as highlighted by Rodríguez Estrada and Davis (2015), to convert the selected quotes of the farmers to paintings that are easier for non-Japanese audiences to capture emphasis of the quotes.

Using a visual illustration has the potential of supplementing the verbal quote to draw audiences' attention to the more comprehensive experiences of the farmers. Visual illustrations can help convey the emotions and sensations that farmers were trying to convey in the interviews in an imaginative way. To address the common misconceptions related to dementia, Bartlett (2013) used cartoon-style drawings to portray the lifeworld of dementia patients in a playful way with 
imaginative scenes in an exhibition. The exhibition received positive feedback, and the cartoons were able to generate fluid and open-ended interpretations. This example shows that illustrations can relate nonverbal connotations to readers of one's research in a metaphorical way. In striving for this, the hope is to inspire the reader to take these aspects into account in understanding the mindsets and practices of farmers. For instance, by just reading the following quote, the embodied aspect of learning mentioned by the farmer can easily be overlooked. The quote can be seen as being merely about cognitive understanding of farming knowledge. In fact, during the conversation the farmer did not separate the cognitive aspect of learning from the embodied one in the quote: how he feels hopeful and is looking forward to reaching the embodied level, more than the fact that he needs more confidence and experiences. It is difficult to capture his emphasis just by reading the quote:

I need more experiences, many things can change the condition... soil, water, weather and everything, I need more confidence in what I am actually doing, then I can move on after 2-3 year. What I have learnt from books and my mentor will be more in my body. I will feel more confident and have an actual sense of what I was taught. (Yoshida)

The following is a short account of how the artist interpreted the quotes, how she incorporated aspects that I wanted to highlight and visualize the quote.

Figure 9.4 shows a simple and subtle scene of a farmer touching and checking the soil and seedling with two hands: the artist intended to use this ordinary moment to convey different meanings expressed in the quote. She focused on the word 'soil' and used it as an anchor to link different aspects of learning Yoshida mentioned in the quote. In the opinion of the artist, soil shows the impact of weather, humidity and the environment; soil also shapes the condition of plants. Since farmers accumulate knowledge of soil through experience and practices, the artist uses the act of touching and caring of soil in Fig. 9.4 to symbolize the accumulation of knowledge as indicated in the quote. As I wanted to highlight the aspect of learning from an embodied level in the illustration, the artist presented the farmer without a head. The 


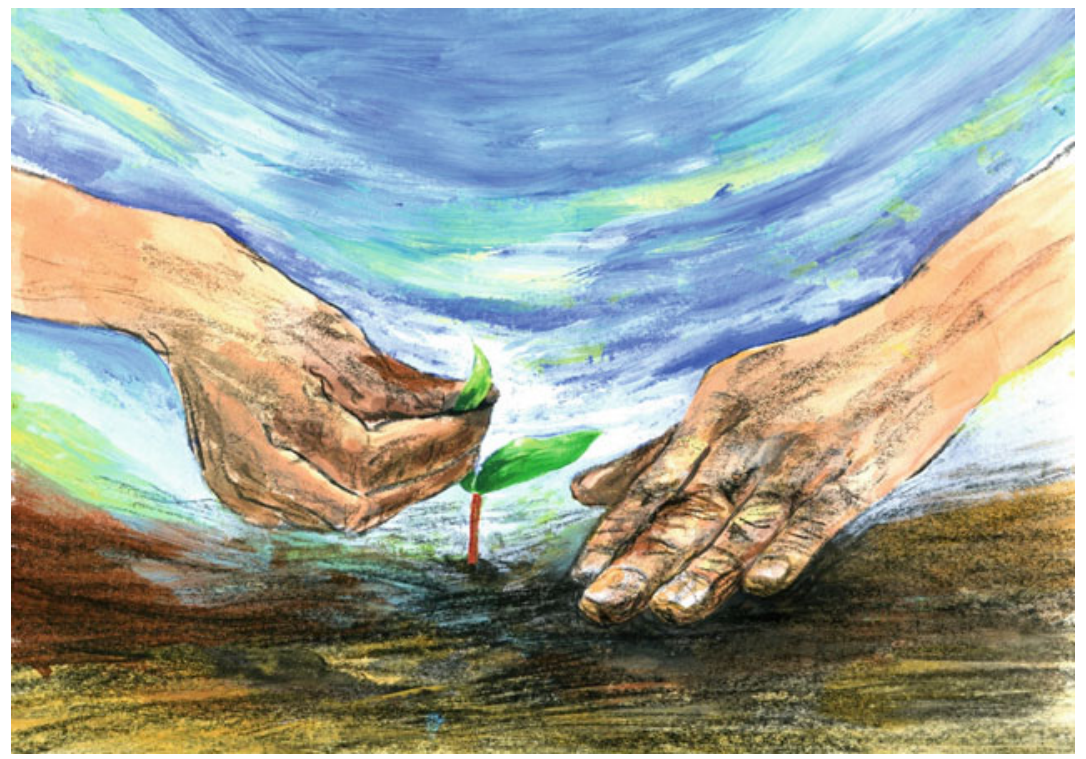

Fig. 9.4 Illustration of a farmer caring for the plant through his body to accumulate knowledge and experience (Source Megumi Hirose)

blue background has two implications: first, it shows a blue sky and aims to bring a positive and hopeful emotion that the quote expressed; second, the background meanwhile can also be the chest of the farmer, the combination of different colours signifies the fluidity of affect and feelings he has for the plant in his heart.

Illustrations can also visualize in a more realistic way the scene of how farmers interact with non-humans through various sensuous experiences in their farming practices. In the following quote, Yanaga shared how she used her body to feel and care for the plants to understand their condition:

The scent, you can smell it... you can feel it, touch it and you can taste it. If the crop is not doing well, I can see the failure from their shapes. If you look at a tomato closely, you feel the hair.... (Yanaga) 
When she expressed the quote, she was excited and showed how these interactions with the plants and attention to small details motivated her in her everyday farming life. However, these emotions are also not explicit in the quote. In Fig. 9.5, the artist wanted to highlight the love and affection that a farmer develops towards her plants and tomatoes in the process of nurturing and caring for them. The facial expression of the farmer in Fig. 9.5 communicates such excitement when she is examining the tomato through the touch of her hand and her smelling the tomato. The farmer is surrounded and embraced by her flourishing plants in the composition of the illustration; it conveys the reciprocity of care and happiness between the two, in which the plants flourish because of the care of the farmer, and the farmer is happy when the plants grow well.

Similarly, Shibata illustrated how he plants rice by hand. In the quote, it is difficult to imagine at the cognitive level how human hands can transfer energy to the plants, within a western scientific understanding. The 'energy' he is referring to is related to the concept of 'ki-energy'

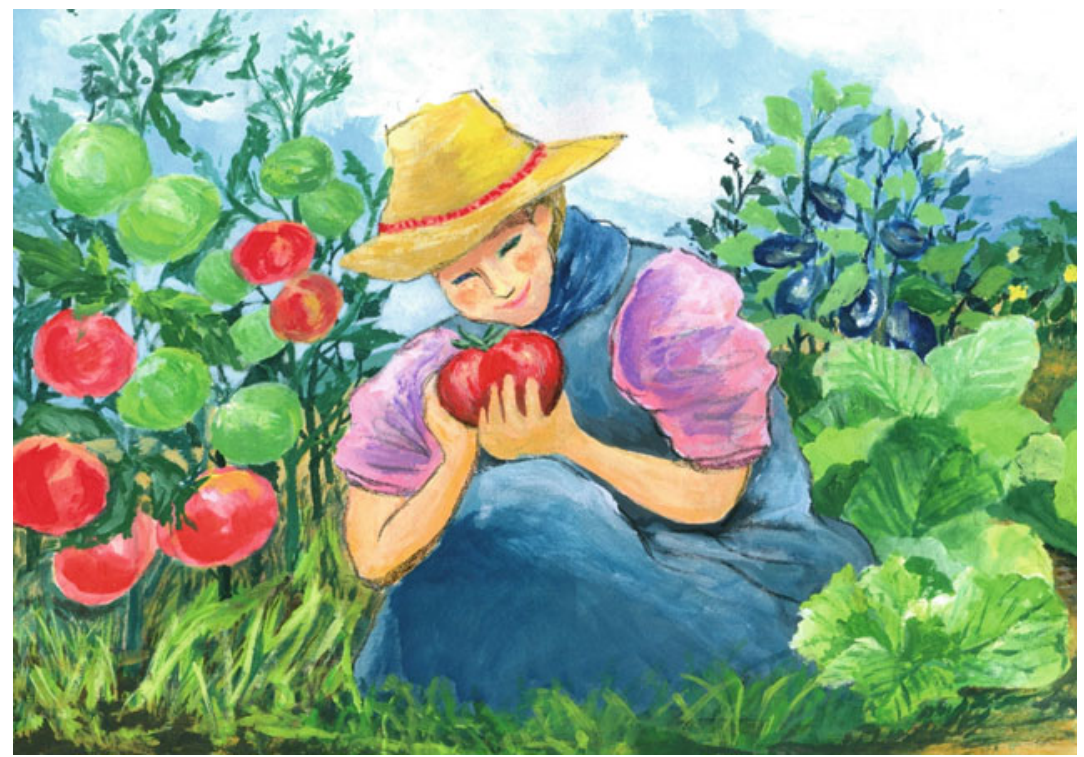

Fig. 9.5 Illustration of a farmer appreciating her tomato like an artwork (Source Megumi Hirose) 
in Japanese culture. The meanings of 'ki-energy' are very different from what the English word 'energy' conveys: 'ki-energy' signifies a vital force that flows between animated things and inanimate things in the world. In the context of this quote, it is a force that flows between the body of the farmer, the rice plants and the soil:

We like planting rice by hands because it makes rice more delicious. When we use our hands to touch the plants, some good energy is transmitted to the plants and the Earth. I believe in the power of it, that's why I want more people to be involved in my farming, and I can get a lot of good power from a variety of people. (Shibata)

Both the artist and I identified 'ki-energy' as the key idea to be highlighted in the illustration. The first image that popped up in her mind from the quote is a farmer transplanting rice with their hands in a Satoyama landscape. Being an incomer from an urban area, the artist does not just experience Satoyama through the visual landscape but also the smell in the air. She believes that a lot of energy is also stored in the air in the landscape. In Fig. 9.6, the white path signifies the moving of 'ki-energy' in the air embracing the farmers, the villages, mountains and forests. The white path also visualizes how 'ki-energy' is generated from manual rice transplantation, an aspect that I wanted to highlight. As the farmer transplants the rice plants using his hands, the 'ki-energy' gathers and spreads to the villages between the rice fields and the mountains. It signifies the process of how the delicious rice produced by traditional rice planting method brings good energy to people. The illustration also highlights that rice transplantation by hand involves more than the physical movement and visible touch of the plants. It also includes the invisible connections that the farmer feels with the plants and soil in the process of transplanting them. 


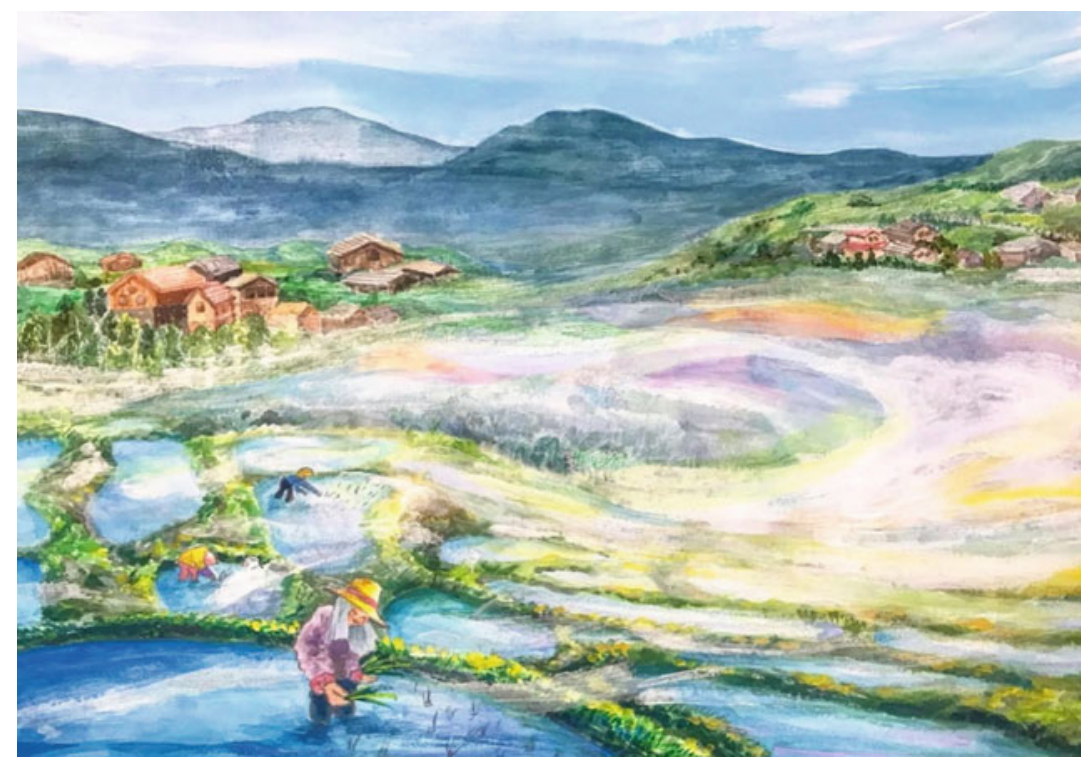

Fig. 9.6 Illustration of a farmer enjoying rice planting by hands to cultivate the circulation of 'ki-energy' between his body, soil and the plants (Source Megumi Hirose)

\section{Conclusions: 'Seeing' Meanings Beyond Language}

Visual methods can be a useful tool to unlock the sensibilities of a cross-cultural researcher, or in general a same-cultural researcher who is overly or insufficiently familiar with the cultural context. They allow the researcher to better understand emotions and affects that are neglected in the research practices seeking singularity and certainty in social sciences. Through doing cross-cultural research in Japan, I experienced the insufficiency of language in understanding the experiences, emotions and feelings that farmers associated with their practices and forms of life. This led to many awkward moments when words were exchanged, but did not convey meaning. Using the photos in the interviews allowed me to gain a deeper understanding of the everyday farming life of my respondents in light of their specific cultural context. The photos also 
triggered associations that allowed us to discuss aspects of experiences that are difficult to put into words. Reflecting on what farmers saw, but I could not see, enabled me to co-creatively identify various more-thanrepresentational dimensions they associated with their farming practices, i.e., the emotions and feelings. Reflecting on the cultural constraints during data collection and the resulting difficulties of conveying meanings fully through using only words, I also explored the use of illustrations by a local artist to complement quotes, so as to more fully convey research results to western audiences.

It was through reflecting on the feelings of frustration and embarrassment associated with the language differences that I was able to notice how visual methods can help to uncover different layers of understanding. As noted by Law (2004), method is not just a set of techniques, every method is performative, it depends on what kind of social science we want to practice. Only when I stopped desperately looking for the 'right' words did I become more mindful of how the seeing and unseeing of the farmers reveal a different reality, one that I did not encounter in the literature on farmers in Japan. Indeed, 'method goes with work, and ways of working, and ways of being' (Law, 2004, p. 10). Being a foreign, clumsy and mute body in the field unavoidably influenced the interactions I had with the farmers. My questions often sounded strange to them, as I was not able to formulate my questions in a way that was meaningful in the cultural context of rural Japan. Fortunately, having a local interpreter who already knew most of the farmers helped to encourage the farmers to be more generous in sharing their thoughts and experiences. The farmers did not feel offended and they were willing to explain their seeing in a more in-depth way, making meanings and implications explicit that were a taken-for-granted part of their experiences.

I have found being a cross-cultural researcher, in the context of this field research, in some ways like being a blind person-I could not see directly how experiences and practices are tied to culture. However, through the incorporation of visual methods, this has not been a limitation; rather, the visual methods helped me to capture meanings hidden behind language. I suggest that cross-cultural research is a good opportunity to broaden, to subvert and to remake research methods. It clearly 
reveals that the world is so complex that we cannot fully grasp it. It also inspires us to transcend the habit of looking for security and the definite; to recognize the importance of opening up our sensibilities to uncover multiple realities through methods that might otherwise be dismissed as slow, vulnerable and imprecise.

Acknowledgements This research received funding from the European Union's Horizon 2020 research and innovation programme under the Marie Sklowdoska-Curie Grant Agreement No. 765389.

\section{References}

Anderson, B. (2006). Becoming and being hopeful: Towards a theory of affect. Environment and Planning d: Society and Space, 24(5), 733-752. https:// doi.org/10.1068/d393t

Anderson, B., \& Harrison, P. (2016). Taking-place: Non-representational theories and geography. Routledge.

Bagnoli, A. (2009). Beyond the standard interview: The use of graphic elicitation and arts-based methods. Qualitative Research, 9(5), 547-570. https:// doi.org/10.1177/1468794109343625

Banks, M. (2001). Visual methods in social research. Sage.

Bartlett, R. (2013). Playing with meaning: Using cartoons to disseminate research findings. Qualitative Research, 13(2), 214-227. https://doi.org/10. 1177/1468794112451037

Beilin, R. (2005). Photo-elicitation and the agricultural landscape: 'Seeing' and 'telling' about farming, community and place. Visual Studies, 20(1), 56-68. https://doi.org/10.1080/14725860500064904

Brown, R. D., \& Yokohari, M. (2003). Ideological contributions of satoyamas. In K. Takeuchi, R. D. Brown, I. Washitani, A. Tsunekawa, \& M. Yokohari (Eds.), Satoyama: The traditional rural landscape of Japan (pp. 1-6). Springer. Campbell, L. K., Svendsen, E. S., Reynolds, R., \& Marshall, V. (2019). Material and social relations in a coastal community garden assemblage. Social \& Cultural Geography, 1-23. https://doi.org/10.1080/14649365. 2019.1658800 
Caretta, M. A. (2015). Situated knowledge in cross-cultural, cross-language research: A collaborative reflexive analysis of researcher, assistant and participant subjectivities. Qualitative Research, 15(4), 489-505. https://doi.org/ 10.1177/1468794114543404

Collier, J., Jr. (1957). Photography in anthropology: A report on two experiments. American Anthropologist, 59(5), 843-859. https://doi.org/10.1525/ aa.1957.59.5.02a00100

Dahl, S., Morris, G., Brown, P., Scullion, L., \& Somerville, P. (2012). Somewhere nowhere. Lives without homes. Salford Housing and Urban Studies Unit.

Darnhofer, I. (2018). Using comic-style posters for engaging participants and for promoting researcher reflexivity. International Journal of Qualitative Methods, 17(1), 1-12. https://doi.org/10.1177/1609406918804716

Davies, G., \& Dwyer, C. (2007). Qualitative methods: Are you enchanted or are you alienated? Progress in Human Geography, 31(2), 257-266. https:// doi.org/10.1177/0309132507076417

Esham, M., Kobayashi, H., Matsura, I., \& Alam, A. (2012). Japanese agricultural cooperatives at crossroads: A review. American-Eurasian Journal of Agricultural and Environmental Sciences, 12(7), 943-953. https://doi.org/10. 5829/idosi.aejaes.2012.12.07.175

Foster, H. (1988). Preface. In H. Foster (Ed.), Vision and visuality (pp. ix-xiv). Bay Press.

Giustini, D. (2019). "It's not just words, it's the feeling, the passion, the emotions": An ethnography of affect in interpreters' practices in contemporary Japan. Asian Anthropology, 18(3), 186-202. https://doi.org/10.1080/ 1683478X.2019.1632546

Gliessman, S. (2017). Agroecology: Building an ecological knowledge-base for food system sustainability. Agroecology and Sustainable Food Systems, 41(7), 695-696. https://doi.org/10.1080/21683565.2017.1335152

Harper, D. (2001). Changing works: Visions of a lost agriculture. University of Chicago Press.

Harper, D. (2002). Talking about pictures: A case for photo elicitation. Visual Studies, 17(1), 13-26. https://doi.org/10.1080/14725860220137345

Harrison, P. (2000). Making sense: Embodiment and the sensibilities of the everyday. Environment and Planning d: Society and Space, 18(4), 497-517. https://doi.org/10.1068/d195t

Harrison, P. (2007). "How shall I say it...?" Relating the nonrelational. Environment and Planning A, 39(3), 590-608. https://doi.org/10.1068/ a3825 
Hitchings, R. (2003). People, plants and performance: On actor network theory and the material pleasures of the private garden. Social \& Cultural Geography, 4(1), 99-114. https://doi.org/10.1080/1464936032000049333

Iwatsuki, K. (2008). Sustainable use of biodiversity, with reference to the Japanese spirit of worshipping nature. In N. Furuta, K. Iwatsuki, H. Nishida, \& M. Kawamichi (Eds.), Conserving nature: A Japanese perspective (pp. 4-11). Biodiversity Network Japan.

Kitagawa, F., Breslin, L., \& Favell, A. (2015). Art place Japan: The EchigoTsumari Art Triennale and the vision to reconnect art and nature. Princeton Architectural Press.

Krzywoszynska, A. (2015). On being a foreign body in the field, or how reflexivity around translation can take us beyond language. Area, 47(3), 311-318. https://doi.org/10.1111/area.12202

Krzywoszynska, A. (2016). What farmers know: Experiential knowledge and care in vine growing. Sociologia Ruralis, 56(2), 289-310. https://doi.org/ $10.1111 /$ soru. 12084

Law, J. (2004). After method: Mess in social science research. London: Routledge. Lorimer, H. (2005). Cultural geography: The busyness of being 'more-thanrepresentational'. Progress in Human Geography, 29(1), 83-94. https://doi. org/10.1191/0309132505ph531pr

Mulgan, A. G. (2005). Where tradition meets change: Japan's agricultural politics in transition. The Journal of Japanese Studies, 31(2), 261-298. https:// doi.org/10.1353/jjs.2005.0053

Pereira, M. D. M., Scharff, C., \& Marhia, N. (2009). Interrogating language difference and translation in social science research: Towards a critical and interdisciplinary approach. Graduate Journal of Social Science, 6(3), 1-12.

Pile, S. (2010). Emotions and affect in recent human geography. Transactions of the Institute of British Geographers, 35(1), 5-20. https://doi.org/10.1111/ j.1475-5661.2009.00368.x

Rodríguez Estrada, F. C., \& Davis, L. S. (2015). Improving visual communication of science through the incorporation of graphic design theories and practices into science communication. Science Communication, 37(1), 140-148. https://doi.org/10.1177/1075547014562914

Rose, G. (2014). On the relation between 'visual research methods' and contemporary visual culture. The Sociological Review, 62(1), 24-46. https:// doi.org/10.1111/1467-954X.12109 
Rose, G., \& Tolia-Kelly, D. P. (2012). Visuality/materiality: Introducing a manifesto for practice. In G. Rose \& D. P. Tolia-Kelly (Eds.), Visuality/materiality: Images, objects and practices (pp. 1-11). Ashgate Publishing Ltd.

Sherren, K., Fischer, J., \& Fazey, I. (2012). Managing the grazing landscape: Insights for agricultural adaptation from a mid-drought photo-elicitation study in the Australian sheep-wheat belt. Agricultural Systems, 106 (1), 7283. https://doi.org/10.1016/j.agsy.2011.11.001

Sherren, K., Fischer, J., \& Price, R. (2010). Using photography to elicit grazier values and management practices relating to tree survival and recruitment. Land Use Policy, 27(4), 1056-1067. https://doi.org/10.1016/j.landusepol. 2010.02.002

Sherren, K., \& Verstraten, C. (2013). What can photo-elicitation tell us about how maritime farmers perceive wetlands as climate changes? Wetlands, 33(1), 65-81. https://doi.org/10.1007/s13157-012-0352-2

Temple, B. (2002). Crossed wires: Interpreters, translators, and bilingual workers in cross-language research. Qualitative Health Research, 12(6), 844-854. https://doi.org/10.1177/104973230201200610

Temple, B., \& Young, A. (2004). Qualitative research and translation dilemmas. Qualitative Research, 4(2), 161-178. https://doi.org/10.1177/ 1468794104044430

Thien, D. (2005). After or beyond feeling? A consideration of affect and emotion in geography. Area, 37(4), 450-454. https://doi.org/10.1111/j. 1475-4762.2005.00643a.x

Tolia-Kelly, D. P. (2006). Affect-An ethnocentric encounter? Exploring the 'universalist' imperative of emotional/affectual geographies. Area, 38(2), 213-217. https://doi.org/10.1111/j.1475-4762.2006.00682.x

Tufte, E. (1997). Visual explanations. Images and quantities, evidence and narrative. Graphics Press.

Turner, S. (2010). Research note: The silenced assistant. Reflections of invisible interpreters and research assistants. Asia Pacific Viewpoint, 51(2), 206-219. https://doi.org/10.1111/j.1467-8373.2010.01425.x

Yokohari, M., \& Bolthouse, J. (2011). Keep it alive, don't freeze it: A conceptual perspective on the conservation of continuously evolving satoyama landscapes. Landscape and Ecological Engineering, 7(2), 207-216. https:// doi.org/10.1007/s11355-010-0116-1 
Open Access This chapter is licensed under the terms of the Creative Commons Attribution 4.0 International License (http://creativecommons.org/ licenses/by/4.0/), which permits use, sharing, adaptation, distribution and reproduction in any medium or format, as long as you give appropriate credit to the original author(s) and the source, provide a link to the Creative Commons license and indicate if changes were made.

The images or other third party material in this chapter are included in the chapter's Creative Commons license, unless indicated otherwise in a credit line to the material. If material is not included in the chapter's Creative Commons license and your intended use is not permitted by statutory regulation or exceeds the permitted use, you will need to obtain permission directly from the copyright holder.

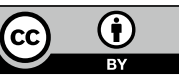

